\title{
Endoscopic resection of small-bowel submucosal nodule
}

The options for management of submucosal nodules in the small bowel are limited. A 67-year-old woman presented for evaluation after positive findings from fecal immunochemical testing. Colonoscopy showed a 2-cm submucosal nodule in the terminal ileum. Superficial biopsies from the lesion were unrevealing. Over-thescope clip (OTSC)-assisted resection was planned. An OTSC (size 12/6, type gc) was applied to the base of the lesion and hot snare resection was performed above the clip ( $\bullet$ Fig. 1, Video 1). The collected tissue was submitted for pathological examination, which showed lipoma. No procedure-related complications were seen.

We conclude that OTSC-assisted resection is a safe management option for submucosal nodules in the small intestine.

Endoscopy_UCTN_Code_TTT_1AQ_2AD

\section{Competing interests: None}

Siddharth B. Javia, Shashideep Singhal

Department of Internal Medicine,

Division of Gastroenterology, Hepatology and Nutrition; University of Texas Medical School at Houston, Texas, USA

\section{Bibliography}

Dol http://dx.doi.org/

10.1055/s-0042-104190

Endoscopy 2016; 48: E111

(C) Georg Thieme Verlag KC

Stuttgart · New York

ISSN 0013-726X

Corresponding author Shashideep Singhal, MD

6431 Fannin Street, MSB 4.232

Houston, Texas 77030

USA

Fax: +1-713-500-6699

sdsinghal@gmail.com

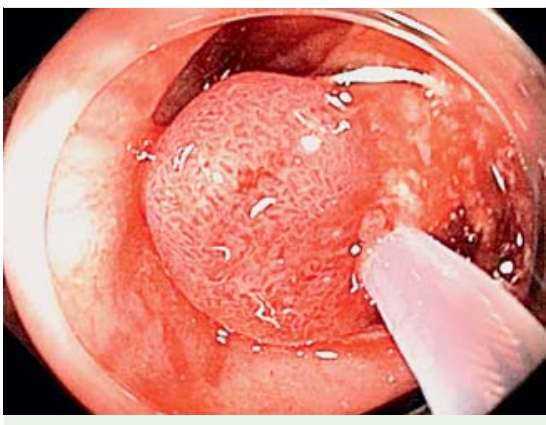

Fig. 1 Hot snare resection of submucosal nodule in the terminal ileum, after placement of an over-the-scope (OTSC) clip at the base of the lesion.

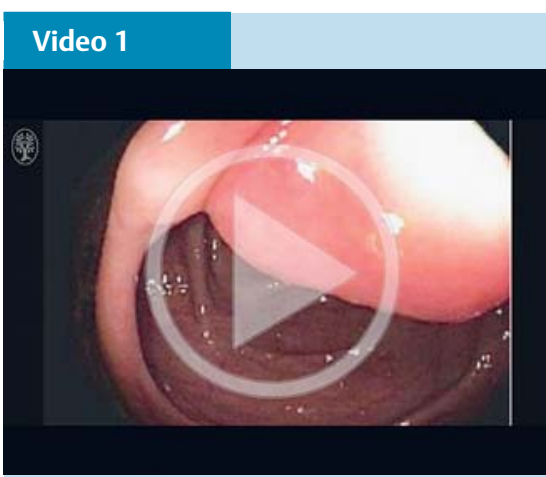

Endoscopic resection of small-bowel submucosal nodule. 